International Journal of Biology, Pharmacy and Allied Seiences (IJBPAS) 'A Bridge Betuen Caboratory and Qnendo' WWW.ijbpas.com

\title{
CYTOCHROMES- A REVIEW
}

HEMA $\mathrm{V}^{1}$, INDUMATHI $\mathrm{M}^{2}$, KAVITHA. $\mathrm{S}^{3}, \mathrm{~V}$. VISHNUPRIYA ${ }^{4}$ AND GAYATHRI. $\mathrm{R}^{5^{*}}$

1, 2: Saveetha Dental College and Hospitals, Saveetha Institute of Medical and Technical Sciences, Saveetha University, Chennai

3: Lecturer, Department of Biochemistry, Saveetha Dental College and Hospitals, Saveetha Institute of Medical and Technical Sciences, Saveetha University, Chennai

4: Professor \& Head, Department of Biochemistry, Saveetha Dental College and Hospitals,

Saveetha Institute of Medical and Technical Sciences, Saveetha University, Chennai

5: Assistant Professor, Department of Biochemistry, Saveetha Dental College and Hospitals,

Saveetha Institute of Medical and Technical Sciences, Saveetha University, Chennai

*Corresponding Author: E Mail: Dr. Gayathri. R: gavathri.sdc@saveetha.com; Tel: $+919567263096$

Received 19 ${ }^{\text {th }}$ March 2021; Revised 20 ${ }^{\text {th }}$ April. 2021; Accepted 19 ${ }^{\text {th }}$ May 2021; Available online $1^{\text {st }}$ Aug. 2021 https://doi.org/10.31032/IJBPAS/2021/10.8.1001

ABSTRACT

Cytochromes are the conjugated proteins consisting of heme as the prosthetic group. They can undergo oxidation and reduction. These proteins are involved in the electron transfer chain which is important in the process of respiration occurring in the mitochondria. There are three types of cytochrome namely cytochrome A, cytochrome B, and cytochrome $\mathrm{C}$. The primary function of Cytochrome $\mathrm{c}$ is synthesis of ATP and it is also involved in intrinsic type 2 apoptosis. Cytochrome P450 is another cytochrome which is present in the microsomes of the liver and plays an important role in the detoxification. This review was aimed to highlight and discuss these cytochromes.

Keywords: Cytochrome, electron transport, mitochondria, cytochrome c, cytochrome $\mathbf{P 4 5 0}$ 


\section{INTRODUCTION}

Cytochromes are compounds consisting of HAEM proteins. They can undergo oxidation and reduction. These proteins are involved in the electron transport chain which is important in the process of respiration occurring in the mitochondria. There are three types of cytochrome namely cytochrome A, cytochrome B, and cytochrome $\mathrm{C}$. The primary function of Cytochrome $\mathrm{C}$ is synthesis of ATP and it is also involved in intrinsic type 2 apoptosis. In cytochrome A, cytochrome B,cytochrome C, heme $\mathrm{A}$, heme $\mathrm{B}$,heme $\mathrm{C}$ are the prosthetic group respectively. Cytochrome $\mathrm{P} 450$ is another cytochrome which is present in the microsomes of the liver and plays an important role in detoxification, drug metabolism. The most abundant CYP isoform is CYP3A4 in adult liver constituting about $29 \%$ of total CYP protein and for which reason it is the most important enzyme in drug metabolism [1]. Charles A. discovered the cytochromes in the year 1886 . Then they were rediscovered by David Keilin in the year 1925 and he also discovered their function in cell respiration [2]. Cytochrome c oxidase is a molecular nanomachine that transports energy derived from redox reaction into proton motive forces across a biological membrane [3]. Previously our team has a rich experience in working on various research projects across multiple disciplines [4-18].

\section{Respiratory chain}

Cytochrome aa3 is also called cytochrome oxidase. The function of cytochrome aa3 is to convert ferricytochrome $\mathrm{c}$ to the $\mathrm{Fe}^{3+}$ form. Then it transfers the reducing equivalents gained in this reaction to the molecular oxygen and reduces it to water. The cytochrome oxidase reaction utilises over $95 \%$ of the oxygen employed by the organisms and gives energy needed for the living beings. Hence it is the most important reaction taking in the body. In the oxidation process, energy released is utilised to pump $\mathrm{H}+$ protons actively from the mitochondrial matrix through the inner mitochondrial membrane into the inter membrane space [19]. This leads to the creation of proton gradient across the inner mitochondrial membrane, lower proton concentration is seen within the matrix space and the outside having a higher proton concentration. With the help of a chain of three large protein complexes namely NADH-Q oxidoreductase, cytochrome c oxidoreductase and cytochrome c oxidase, electrons are transferred from NADH to oxygen. The high energy electrons of NADH enter the 
respiratory chain at $\mathrm{NADH} \quad \mathrm{Q}$ oxidoreductase. Ubiquitous is the entry site for electrons from FADH2 of flavoproteins and the electrons flow from ubiquinol to cytochrome $\mathrm{c}$ through $\mathrm{Q}$ cytochrome $\mathrm{c}$ oxidoreductase. The transmembrane proton transport is known as Q cycle [20].

\section{Cytochrome oxidase}

Cytochrome oxidase consists of 8 to 13 polypeptide subunits, two hemes, a and a3, and two copper atoms. Cytochrome oxidase or complex 4 is one of the largest transmembrane protein complexes found in bacteria and eukaryotes in the mitochondria. This is the last enzyme in the electron transport chain. This enzyme catalyses the transfer of electrons from ferricytochrome c to molecular oxygen and then to water. If the cytochrome oxidase is inhibited, cyanide,azide and carbon monoxide will bind to cytochrome oxidase and inhibits function of protein and leads to chemical asphyxiation. The two main classes of cytochrome oxidase are cytochrome c oxidases, and quinol oxidases [21]. Cytochrome oxidase also acts as an metabolic marker for neuronal activity. The brain is composed of heterogeneous groups of neurons. Cytochrome oxidase is used as a metabolic marker for neuronal activity because of the tight coupling between neuronal activity and oxidative energy metabolism. Cytochrome oxidase is also called as cytochrome aa3 because the protein bound harms are functionally and spectroscopically different [22].

\section{Cytochrome c}

Cytochrome $\mathrm{c}$ is a hemoprotein located between the inner and outer mitochondrial membranes. It is a single polypeptide chain consisting of 104 to 112 amino acids, heme is the prosthetic group. Cytochrome c has a major role in oxidative phosphorylation and apoptosis. Apoptosis, or programmed cell death, involves the maintenance of cell homeostasis by the elimination of damaged cells. Lack of regulation of apoptosis may lead to diseases, such as cancers, immune diseases, and neurodegenerative disorders. The execution of apoptosis requires caspases, which are a subfamily of cysteine proteases. In caspase activation pathway, a variety of apoptotic stimuli cause the release of cytochrome c from mitochondria, which results in induction of a series of biochemical reactions and leads to caspase activation and subsequent cell death [23]. In eukaryotes cytochromes c plays a vital role in cell respiration and aerobic energy production. Even though the surface area at which the reaction occurs is less than $1 \%$ of the total surface of the protein, electron transfer takes 
place very efficiently. The amino acid sequences of the cytochromes $\mathrm{c}$ of eukaryotes have provided a very interesting association between the structure of protein and the evolutionary relatedness of different taxonomic groups. Cytochrome $\mathrm{c}$ is also involved in the catalysis of several redox reactions such as hydroxylation and aromatic oxidation. Bacterial cytochrome c also functions as a nitrite reductase. Cytochrome $\mathrm{c}$ also acts as an antioxidative enzyme in the mitochondria. It is also used to find out the peroxide production in biological systems [24].

\section{Cytochrome reductase}

The cytochrome reductase complex is an integral membrane protein system. There are multiple subunits, composed of two cytochrome $b$ molecules, one nonheme iron protein, and one cytochrome c1. The two cytochrome $b$ hemes are chemically identical as in the case of the oxidase, but they differ in their protein environments. The cytochrome reductase complex is reduced by reaction involving the reduced form of lipophilic coenzyme Q, dissolved within the inner mitochondrial membrane. Coenzyme Q gets reduced by the NADH dehydrogenase, succinate dehydrogenase, and other systems [25].

\section{Other cytochromes}

Apart from the cytochromes of mitochondrial respiratory chain, animals have a heme protein, known as cytochrome $\mathrm{P} 450$, present in the liver and adrenal cortex. In the liver it act as an integral part of a mono-oxygenase system that can utilize oxygen and the reduced form of the coenzyme NADPH, to hydroxylate a large variety of foreign substances and drugs and hence be involved in the detoxification reaction. In the adrenal it is involved in the hydroxylation of steroid precursors in the biosynthesis of hormones of adrenocortex [26].

\section{Cytochrome P450}

Cytochromes P450 enzymes constitute a large superfamily of haem-thiolate proteins participating in the metabolism of a wide variety of both exogenous and endogenous compounds [27]. These proteins were first discovered in 1955 in rat liver microsomes and the characteristic feature include the intense absorption band at $450 \mathrm{~nm}$ in the presence of carbon monoxide [28]. The cytochrome $\mathrm{P} 450$ or otherwise known as mixed function monooxygenases are situated on the smooth endoplasmic reticulum of cells, but predominantly found in the liver and small intestine. They are responsible for the oxidative metabolism of a variety of compounds, including many drugs [29]. They 
convert the lipophilic drugs to more polar substances which can be easily eliminated by the kidneys. The metabolites are normally less active compared to the parent compound, however some drugs are biotransformed to pharmacologic active agents. Sometimes the metabolites can be toxic, teratogenic or carcinogenic [30]. The P450-containing monooxygenases can be divided into two main types, bacterial/mitochondrial which is type I and microsomal which is type II. Mitochondrial P450 systems contain three compounds: a FAD containing flavoprotein (also known as NADPH or NADHdependent reductase), an iron-sulfur protein and P450. The eukaryotic microsomal P450 system has two components: NADPH:P450 reductase, a flavoprotein containing both FAD and FMN, and P450. CPR is a fusion protein consisting of domains which are homologous to ferredoxin: NADP+ reductases (FAD domain) and flavodoxin (FMN domain) [31]. All the P450 containing monooxygenases explained so far share similar structural and functional domain architecture. A domain is a polypeptide that exists as an independently folding unit and possesses a certain function. Hence there are no basic differences between the protein domain and the individual protein component. All the P450 systems can be considered as three-domain systems: NADHor NADPH-dependent FAD containing reductase, an iron-sulfur protein (in a threecomponent system) or FMN-binding domain (in a two- and one component system) and P450 domain (haem domain) [32] Our institution is passionate about high quality evidence based research and has excelled in various fields [33-39]. We hope this study adds to this rich legacy.

\section{CONCLUSION}

Cytochromes are the conjugated proteins that contain heme as the prosthetic group. The principal biological function of cytochromes in cells of plants, animals, and microorganisms is to participate in the energy conversion processes such as respiration and photosynthesis. The cytochrome c plays an important role not only in oxidative phosphorylation, but also in apoptosis. Cytochrome c release from mitochondria induces a series of biochemical reactions that result in caspase activation and subsequent cell death, which represents the intrinsic pathway of apoptosis. And cytochrome $\mathrm{P} 450$ enzymes constitute a family of proteins which are involved in the metabolism of a variety of both endogenous and exogenous compounds. Thus these heme proteins play an integral role in the energy 
metabolism and in the elimination of toxic or forein substances as well.

\section{ACKNOWLEDGEMENT}

This research was done under the supervision of the Department of Research of Saveetha Dental College and Hospitals. We sincerely show gratitude to the corresponding guides who provided insight and expertise that greatly assisted the research.

\section{CONFLICTS OF INTEREST}

None declared

\section{REFERENCES}

[1] Keilin D. The History of Cell Respiration and Cytochrome. CUP Archive; 1966.416 p.

[2] Liu J, Chakraborty S, Hosseinzadeh $\mathrm{P}, \mathrm{Yu} \mathrm{Y}$, Tian S, Petrik I, et al. Metalloproteins Containing Cytochrome, Iron-Sulfur, or Copper Redox Centers. Chem Rev. 2014 Apr 23; 114(8): 4366-469.

[3] Omiecinski CJ, Remmel RP, Hosagrahara VP. Concise review of the cytochrome P450s and their roles in toxicology. Toxicol Sci. 1999 Apr $1 ; 48(2): 151-6$.

[4] Neelakantan P, Sharma S, Shemesh $\mathrm{H}$, Wesselink PR. Influence of Irrigation Sequence on the Adhesion of Root Canal Sealers to Dentin: A Fourier Transform Infrared
Spectroscopy and Push-out Bond Strength Analysis. J Endod. 2015 Jul; 41(7): 1108-11.

[5] Sathish T, Karthick S. Wear behaviour analysis on aluminium alloy 7050 with reinforced $\mathrm{SiC}$ through taguchi approach. J Jpn Res Inst Adv Copper-Base Mater Technol. 2020 May; 9(3): 3481-7.

[6] Patil SB, Durairaj D, Suresh Kumar G, Karthikeyan D, Pradeep D. Comparison of Extended Nasolabial Flap Versus Buccal Fat Pad Graft in the Surgical Management of Oral Submucous Fibrosis: A Prospective Pilot Study. J Maxillofac Oral Surg. 2017 Sep; 16(3): 312-21.

[7] Abdul Wahab PU, Senthil Nathan P, Madhulaxmi M, Muthusekhar MR, Loong SC, Abhinav RP. Risk Factors for Post-operative Infection Following Single Piece Osteotomy. J Maxillofac Oral Surg. 2017 Sep; 16(3): 328-32.

[8] Eapen BV, Baig MF, Avinash S. An Assessment of the Incidence of Prolonged Postoperative Bleeding After Dental Extraction Among Patients on Uninterrupted Low Dose Aspirin Therapy and to Evaluate the Need to Stop Such Medication Prior 
to Dental Extractions. J Maxillofac

Oral Surg. 2017 Mar; 16(1): 48-52.

[9] Wahab PUA, Madhulaxmi M, Senthilnathan P, Muthusekhar MR, Vohra Y, Abhinav RP. Scalpel Versus Diathermy in Wound Healing After Mucosal Incisions: A SplitMouth Study. J Oral Maxillofac Surg. 2018 Jun; 76(6): 1160-4.

[10] Jeevanandan G, Govindaraju L. Clinical comparison of Kedo-S paediatric rotary files vs manual instrumentation for root canal preparation in primary molars: a double blinded randomised clinical trial [Internet]. Vol. 19, European Archives of Paediatric Dentistry. 2018. p. 273-8. Available from: http://dx.doi.org/10.1007/s40368018-0356-6

[11] Samuel SR, Acharya S, Rao JC. School Interventions-based Prevention of Early-Childhood Caries among 3-5-year-old children from very low socioeconomic status: Two-year randomized trial. J Public Health Dent. 2020 Jan; 80(1): 51-60.

[12] Mehta M, Deeksha, Tewari D, Gupta G, Awasthi R, Singh H, et al. Oligonucleotide therapy: An emerging focus area for drug delivery in chronic inflammatory respiratory diseases. Chem Biol Interact. 2019 Aug 1; 308: 206-15.

[13] Ezhilarasan D, Sokal E, Najimi M. Hepatic fibrosis: It is time to go with hepatic stellate cell-specific therapeutic targets. Hepatobiliary Pancreat Dis Int. 2018 Jun; 17(3): 192-7.

[14] Rajeshkumar S, Menon S, Venkat Kumar S, Tambuwala MM, Bakshi HA, Mehta M, et al. Antibacterial and antioxidant potential of biosynthesized copper nanoparticles mediated through Cissus arnotiana plant extract [Internet]. Vol. 197, Journal of Photochemistry and Photobiology B: Biology. 2019. p. 111531. Available from: http://dx.doi.org/10.1016/j.jphotobio 1.2019 .111531

[15] Ravindiran M, Praveenkumar C. Status review and the future prospects of CZTS based solar cell A novel approach on the device structure and material modeling for CZTS based photovoltaic device. Renewable Sustainable Energy Rev. 2018 Oct; 94: 317-29.

[16] Ramamoorthi S, Nivedhitha MS, 
Divyanand MJ. Comparative

evaluation of postoperative pain after using endodontic needle and EndoActivator during root canal irrigation: A randomised controlled trial. Aust Endod J. 2015 Aug; 41(2): 78-87.

[17] Malli Sureshbabu N, Selvarasu K, V JK, Nandakumar M, Selvam D. Concentrated Growth Factors as an Ingenious Biomaterial in Regeneration of Bony Defects after Periapical Surgery: A Report of Two Cases. Case Rep Dent. 2019 Jan 22; 2019: 7046203.

[18] Manivannan I, Ranganathan S, Gopalakannan S, Suresh S, Nagakarthigan K, Jubendradass R. Tribological and surface behavior of silicon carbide reinforced aluminum matrix nanocomposite. Surf Interfaces. 2017 Sep; 8: 127-36.

[19] Cascorbi I. Polymorphic cytochrome P450 2D6 as the responsible enzyme of activation [Internet]. Oxford Medicine Online. 2018. Available from: http://dx.doi.org/10.1093/med/9780 198834359.003.0079

[20] Stock D, Leslie AG, Walker JE. Molecular architecture of the rotary motor in ATP synthase. Science. 1999 Nov 26; 286(5445): 1700-5.

[21] Lodish H, Berk A, Zipursky SL, Matsudaira P, Baltimore D, Darnell J. Molecular cell biology 4th edition. National Center for Biotechnology Information, Bookshelf. 2000; 9.

[22] Keilin D, Hartree EF, Hartree EF. Cytochrome and cytochrome oxidase. Proceedings of the Royal Society of London Series B Biological Sciences. 1939 May 18; 127(847): 167-91.

[23] Jiang X, Wang X. Cytochrome Cmediated apoptosis. Annu Rev Biochem. 2004; 73: 87-106.

[24] Hüttemann M, Pecina $P$, Rainbolt M, Sanderson TH, Kagan VE, Samavati L, et al. The multiple functions of cytochrome $\mathrm{c}$ and their regulation in life and death decisions of the mammalian cell: From respiration to apoptosis. Mitochondrion. 2011 May; 11(3): 369-81.

[25] Berg JM, Tymoczko JL, Stryer L. The respiratory chain consists of four complexes: three proton pumps and a physical link to the citric acid cycle. Biochemistry. 2002; 5: 320- 
3.

[26] Riddick DS, Ding X, Wolf CR, Porter TD, Pandey AV, Zhang Q-Y, et al. NADPH-cytochrome P450 oxidoreductase: roles in physiology, pharmacology, and toxicology. Drug Metab Dispos. 2013 Jan; 41(1): 1223.

[27] Degtyarenko KN. Structural domains of P450-containing monooxygenase systems. Protein Eng. 1995 Aug; 8(8): 737-47.

[28] Flück CE, Pandey AV. Clinical and biochemical consequences of p450 oxidoreductase deficiency. Endocr Dev. 2011; 20: 63-79.

[29] Buck ML. The cytochrome P450 enzyme system and its effect on drug metabolism. Pediatr Pharmacother. 1997; 3(5): 211-6.

[30] Meyer JM, Rodvold KA. Drug biotransformation by the cytochrome P-450 enzyme system. Infect Med. 1996; 13: 452-73.

[31] Smith GC, Tew DG, Wolf CR. Dissection of NADPH-cytochrome P450 oxidoreductase into distinct functional domains. Proc Natl Acad Sci U S A. 1994 Aug 30; 91(18): 8710-4.

[32] Lucas MF, Rousseau DL, Guallar V.
Electron transfer pathways in cytochrome c oxidase. Biochim Biophys Acta. 2011 Oct; 1807(10): 1305-13.

[33] Vijayashree Priyadharsini J. In silico validation of the non-antibiotic drugs acetaminophen and ibuprofen as antibacterial agents against red complex pathogens. J Periodontol. 2019 Dec; 90(12): 1441-8.

[34] Ezhilarasan D, Apoorva VS, Ashok Vardhan N. Syzygium cumini extract induced reactive oxygen species-mediated apoptosis in human oral squamous carcinoma cells. J Oral Pathol Med. 2019 Feb; 48(2): 115-21.

[35] Ramesh A, Varghese S, Jayakumar ND, Malaiappan S. Comparative estimation of sulfiredoxin levels between chronic periodontitis and healthy patients - A case-control study. J Periodontol. 2018 Oct; 89(10): 1241-8.

[36] Mathew MG, Samuel SR, Soni AJ, Roopa KB. Evaluation of adhesion of Streptococcus mutans, plaque accumulation on zirconia and stainless steel crowns, and surrounding gingival inflammation in primary .... Clin Oral Investig 
[Internet]. 2020; Available from:

https://link.springer.com/article/10.1

007/s00784-020-03204-9

[37] Sridharan G, Ramani P, Patankar S, Vijayaraghavan R. Evaluation of salivary metabolomics in oral leukoplakia and oral squamous cell carcinoma. J Oral Pathol Med. 2019 Apr; 48(4): 299-306.

[38] Pc J, Marimuthu T, Devadoss P. Prevalence and measurement of anterior loop of the mandibular canal using CBCT: A cross sectional study. Clin Implant Dent Relat Res [Internet]. 2018; Available from: https://europepmc.org/article/med/2 9624863

[39] Ramadurai N, Gurunathan D, Samuel AV, Subramanian E, Rodrigues SJL. Effectiveness of 2\% Articaine as an anesthetic agent in children: randomized controlled trial. Clin Oral Investig. 2019 Sep; 23(9): 3543-50. 